\title{
DEVELOPMENT OF EQUIPMENT TO SEPARATE NONTHERMAL AND THERMAL EFFECTS OF RADIO FREQUENCY ENERGY ON MICROORGANISMS
}

\author{
D. J. Geveke ${ }^{1 *}$, M. Kozempel ${ }^{1}$, C. Brunkhorst ${ }^{2}$ \\ 'U.S. Department of Agriculture \\ Eastern Regional Research Center \\ 600 East Mermaid Lane \\ Wyndmoor, PA 19038 \\ ${ }^{2}$ Princeton University \\ Plasma Physics Laboratory \\ P.O. Box 451 \\ Princeton, NJ 08543
Prepared for presentation at 1999 Annual Meeting, Dallas, TX, 31 Oct. - 5 Nov Unpublished \\ AIChE shall not be responsible for statements or opinions contained in papers or printed in its \\ publications
}

\begin{abstract}
A radio frequency (RF) dielectric heater has been developed for isolating thermal and nonthermal effects of RF energy on microorganisms in liquid foods. The modified heater enables the simultaneous application of RF energy and removal of thermal energy from the liquids. A doublepipe heat exchanger is an integral part of the heater. The outer pipe is made of Teflon. The inner pipe is made of stainless steel that is grounded in the RF circuit. Liquid food flows through the annular region between the two concentric pipes. Cooling water flows through the stainless steel pipe. The food in the annular region absorbs the RF energy. Concurrently, the cooling water flowing in the inner pipe removes the thermal energy from the food, thus controlling the temperature.
\end{abstract}

\section{Introduction}

The potential benefits of minimally processing foods include maintaining fresh-like qualities and nutrients as well as reducing processing costs. The use of radio frequency $(R F)$ and microwave electromagnetic energy to nonthermally inactivate microorganisms in liquid foods has frequently been reported in the literature. Contradictory reports, stating that there are no nonthermal effects, are nearly as prevalent. The purpose of this work was to develop pilot scale, continuous flow equipment that can be used to separate nonthermal from thermal effects of RF energy on microorganisms. The equipment described in this paper is capable of applying RF energy to liquids while simultaneously removing thermal energy from the liquids. The use of turbulent flow minimizes the possibility of localized heating that could lead to erroneous conclusions.

\section{Materials and Methods}

The RF equipment is a Model FH-10, $15 \mathrm{~kW}$ Radio Frequency Heater (PSC, Inc., Cleveland, OH). The oven consists of a power oscillator, including an EIMAC $3 \mathrm{CX} 10000 \mathrm{H} 3$ triode. The plate supply is an unfiltered three-phase transformer-rectifier, with $480 \mathrm{VAC}$ input. The absence of a filter capacitor minimizes stored energy and thus the hazards to the tube and personnel. The plate voltage is set by a SCR controller, and is variable from 2 to $12 \mathrm{kV}$. The plate voltage controls the level of the RF power.

*Corresponding Author. Telephone: (215) 233-6507; Fax: (215) 233-6795; Email: dgeveke@arsertc.gov.

Mention of brand or firm name does not constitute an endorsement by the U.S. Department of Agriculture above others of a similar nature not mentioned. 


\section{DISCLAIMER}

This report was prepared as an account of work sponsored by an agency of the United States Government. Neither the United States Government nor any agency thereof, nor any of their employees, make any warranty, express or implied, or assumes any legal liability or responsibility for the accuracy, completeness, or usefulness of any information, apparatus, product, or process disclosed, or represents that its use would not infringe privately owned rights. Reference herein to any specific commercial product, process, or service by trade name, trademark, manufacturer, or otherwise does not necessarily constitute or imply its endorsement, recommendation, or favoring by the United States Government or any agency thereof. The views and opinions of authors expressed herein do not necessarily state or reflect those of the United States Government or any agency thereof. 


\section{DISCLAIMER}

Portions of this document may be illegible in electronic image products. Images are produced from the best available original document. 
Experiments were performed in which liquids were supplied with RF energy while simultaneously being cooled. The equipment consisted of a double pipe heat exchanger inside a RF chamber. The outer pipe was Teflon ${ }^{\mathrm{TM}}$ that is transparent to RF, whereas the inner pipe was stainless steel through which water flowed to regulate the temperature. Process fluid flowed in the annulus and absorbed the RF energy. Water flowed co-current to the process fluid and removed thermal energy from the process fluid.

The experimental system is shown in Figure 1. It includes an $190 \mathrm{l}$ stainless steel feed tank. A sanitary positive displacement pump, Tri-Clover, Kenosha, WI, model PR3-1M-YH6-ST-S, supplied the feed to the RF heater at a flow rate of $3 \mathrm{~kg} / \mathrm{min}$. The outer pipe of the double pipe heat exchanger had an inner diameter of $3.8 \mathrm{~cm}$. The inner tube had an outer diameter of $2.5 \mathrm{~cm}$. To achieve turbulent flow while maintaining a reasonable treatment time in the RF heater, a second sanitary positive displacement pump, Tri-Clover rotary pump, model PR25-11/2M-UH4-ST-S, recycled the process fluid. The recycle pump circulated the fluid at $9 \mathrm{~kg} / \mathrm{min}$, sufficient to achieve turbulent flow. Based on the feed and recycle rates, the process fluid, on average, passed through the $\mathrm{RF}$ heater four times. The cumulative treatment time in the RF heater was $8.4 \mathrm{~s}$. By adjusting the feed and recycle rates, residence times ranging from $7.3 \mathrm{~s}$ to $16.8 \mathrm{~min}$ can be obtained. Process fluid exited the recycle loop in direct proportion to the feed rate established by the feed pump. The system can be visualized as a continuous stirred tank that receives RF energy.

A fiberoptic thermometer, Luxtron, Santa Clara, CA, model 950, provided the temperatures of the feed tank, water, and process fluid. The temperatures were continuously logged to a data acquisition system.

Exposure levels were measured with a Narda meter, model 8616, and probe, model 8682 (Narda Microwave-East, Hauppauge, NY), that reads directly in percent of the ANSI standard. The ANSI standard has been incorporated into the IEEE C95.1-1999 standard. The ANSI standard for safety levels with respect to human exposure to electromagnetic fields establishes a maximal permissible limit of $4000 \mathrm{~V}^{2} / \mathrm{m}^{2}$. The limit used was for frequencies of $30-300 \mathrm{MHz}$. Below $30 \mathrm{MHz}$, the limit is higher. Although the frequency, with water as the test fluid, was actually $18 \mathrm{MHz}$; the more conservative limit was used because the frequency for other test fluids may be higher.

\section{Results and Discussion}

The initial configuration of the radio frequency (RF) heater consisted of two concentric pipes, as shown in Figure 2. The stainless steel inner pipe was grounded. The outer pipe was made of polypropylene. This assembly was flanked on either side by concave aluminum capacitor plates that coupled RF energy to the test fluid through the polypropylene pipe wall, as shown in Figure 3 . The plates were $7.0 \mathrm{~cm}$ wide and $76.2 \mathrm{~cm}$ long. The spacing from the plates to the pipe was variable. The load capacitor plate spacing was initially set to $10.2 \mathrm{~cm}$ from the polypropylene pipe to the active plate and $6.4 \mathrm{~cm}$ from the pipe to the grounded plate. When operated in this configuration, arcing at the load capacitor hampered coupling of significant power to the test fluid. At the full plate voltage of $12 \mathrm{kV}$, the frequency was 24 $\mathrm{MHz}$ and the delivered power was only $1 \mathrm{~kW}$. In addition, high levels of RF leakage were detected. The holes in the oven where the pipes exit were stuffed with a copper mesh material for RF shielding. The RF leakage was reduced to below $5 \%$ of the ANSI limit for personnel exposure.

The spacing from the capacitor plates to the pipe was reduced to $2.5 \mathrm{~cm}$ to the active plate and 1.3 $\mathrm{cm}$ to the grounded plate. The polypropylene pipe deformed and it was replaced with Teflon. In addition, the configuration of the RF heater was changed so that both plates were connected together (driven in-phase). The plate that was formerly grounded was supported on ceramic insulators. The ground connection to the stainless steel pipe was improved by adding more grounding straps. The 
capacitor plate spacing was also reduced to $0.6 \mathrm{~cm}$. The delivered power increased to $2.4 \mathrm{~kW}$ at which point arcing occurred at the top of the capacitor plate. This demonstrated both the benefit of increased coupling, and the hazard of higher voltage stress at close plate spacing.

To improve arc suppression and allow better coupling, sheets of dielectric material were placed between the capacitor plates and the pipe, in contact with both surfaces. The material was $1.3 \mathrm{~cm}$ polyethylene, and extended beyond the edges of the capacitor plates. This material has a dielectric constant of about 2 which increased the capacitance and thus the coupling of the load capacitor over that of an equal spacing in air. In addition, new capacitor plates were manufactured of $1.0 \mathrm{~cm}$ thick aluminum, $7.6 \mathrm{~cm}$ wide by $91.4 \mathrm{~cm}$ long. The edges were milled with a $1.0 \mathrm{~cm}$ radius, and were bent $60^{\circ}$ for $7.6 \mathrm{~cm}$ at the ends. The new capacitor plates are flat along their short dimension, rather than concave as previously.

At a delivered power $>3.1 \mathrm{~kW}$, arcing was noticed. It was coming from the copper mesh material used to provide a RF shield at the pipe exit holes. The holes were reduced from $12.1 \mathrm{~cm}$ to $5.1 \mathrm{~cm}$ diameter with copper plates, and the gap to the stainless steel pipe was completely enclosed with sections of $2.5 \mathrm{~cm}$ wide copper braid. One end of the copper braid was soldered to the copper plate, and the other clamped to the stainless steel pipe.

Testing of the new configuration produced $4.5 \mathrm{~kW}$. The frequency had dropped to $18 \mathrm{MHz}$ due to the increased capacitance of the load. The RF leakage was greatly reduced. The increased coupling of the new capacitor is due to its flat surface, which brings its entire area into contact with the dielectric plate, resulting in an increase in capacitance. The original capacitor plates were concave and only contacted the dielectric plates at their edges.

The Rexolite insulators for one capacitor plate partially melted, and were replaced with Teflon insulators. The edges of the opening, where the aluminum tank circuit connection passes from the oscillator compartment to the load compartment, were covered with split rubber hose to form a corona shield. In addition, corona shields were made and.installed to eliminate the sharp edge on the radius at the capacitor plate ends. Finally, Teflon studs were installed to keep the dielectric plates centered in the capacitor plates. Satisfactory operation was demonstrated at sustained full power. The load power was $7.84 \mathrm{~kW}$ at a plate input power of $15 \mathrm{~kW}$; this represents an efficiency of $52 \%$. The final mechanical and electrical configurations of the load are shown in Figures 4 and 5.

The geometric arrangement of the capacitor plates and inner tube resulted in the application of a nonuniform RF field to the process fluid; the electric field strength of the fluid nearest the plates was approximately three times that of the fluid farthest from the plates. However, in addition to providing turbulent flow, the recycle minimized the effect of the nonuniformity on the process fluid.

The experimental procedure to isolate nonthermal from thermal effects is to run the process at normal pasteurization temperature, usually at $60-65^{\circ} \mathrm{C}$, and, without changing anything such as power input or product flow rate, to drop the temperature to $\leq 40^{\circ} \mathrm{C}$ using only cooling water in the inner tube. Any microbiological reduction of the product at $\leq 40^{\circ} \mathrm{C}$ would be due to nonthermal effects.

To test solely the performance of the unit, tap water with no added microorganisms was processed at normal pasteurization temperature. As shown in Figure 6, cooling water in the ground pipe quickly reduced the product temperature to $40^{\circ} \mathrm{C}$. Similar results have been obtained with several other liquids including apple cider, beer, and deionized water.

\section{Conclusions}

The RF heater was successfully modified. It is capable of isolating thermal and nonthermal effects due to RF. As such, we will begin testing for nonthermal effects on microorganisms in liquid foods. 


\section{Figure Legends}

Figure 1. Process Flow Sheet of the RF Equipment.

Figure 2. Initial Load Configuration. Capacitor is $76.2 \mathrm{~cm}$ long and $7.0 \mathrm{~cm}$ wide.

Figure 3. Initial Circuit Configuration.

Figure 4. Final Load Configuration.

Figure 5. Final Circuit Configuration.

Figure 6. Thermal vs. Nonthermal Test. Process temperature controlled by only varying the cooling water inlet temperature. All other parameters kept constant: RF power supplied, $19 \mathrm{~kW}$; feed rate, 3 $\mathrm{kg} / \mathrm{min}$; feed temperature, $11^{\circ} \mathrm{C}$; recycle pump rate, $9 \mathrm{~kg} / \mathrm{min}$. Each line consists of 324 data points. 


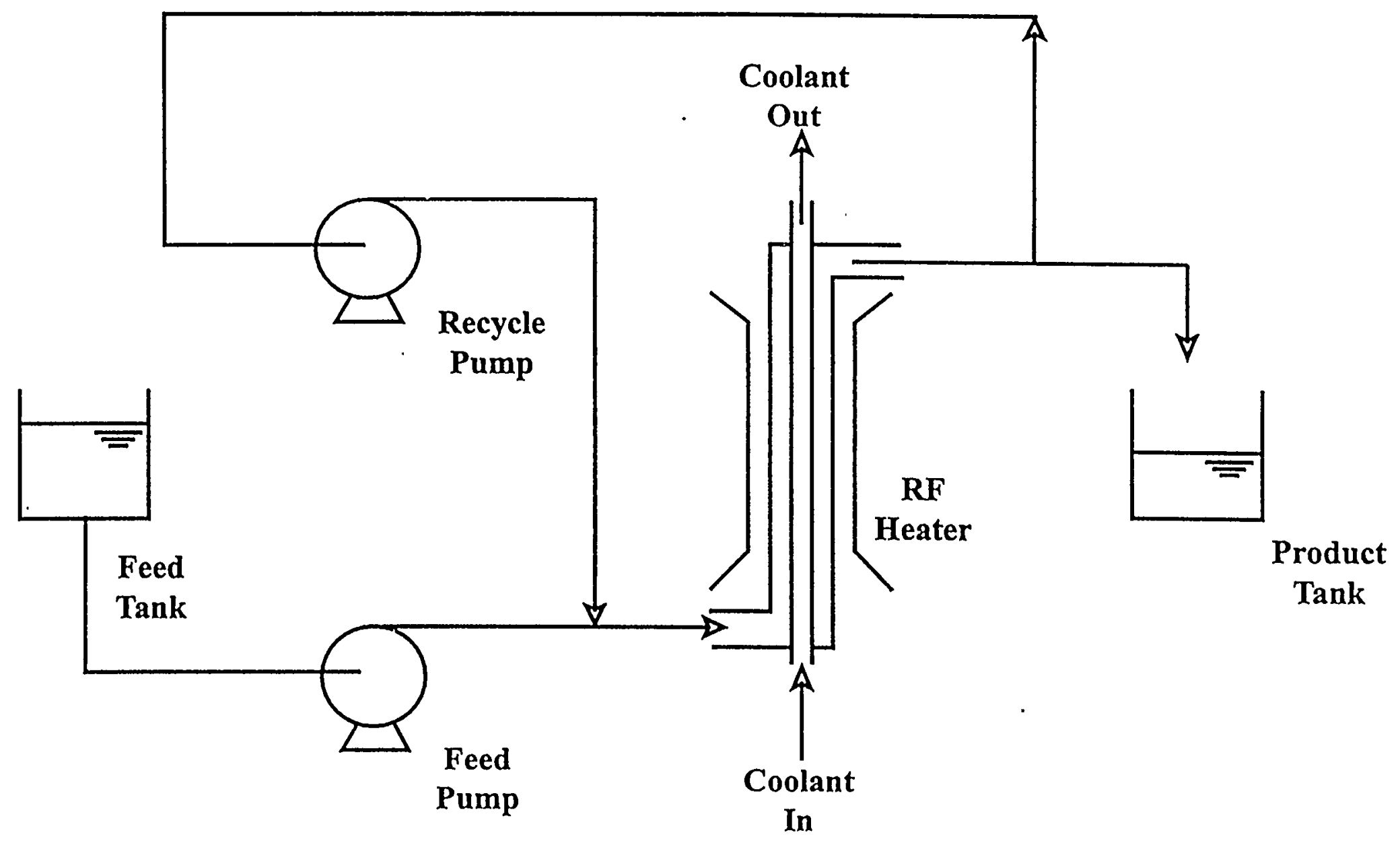




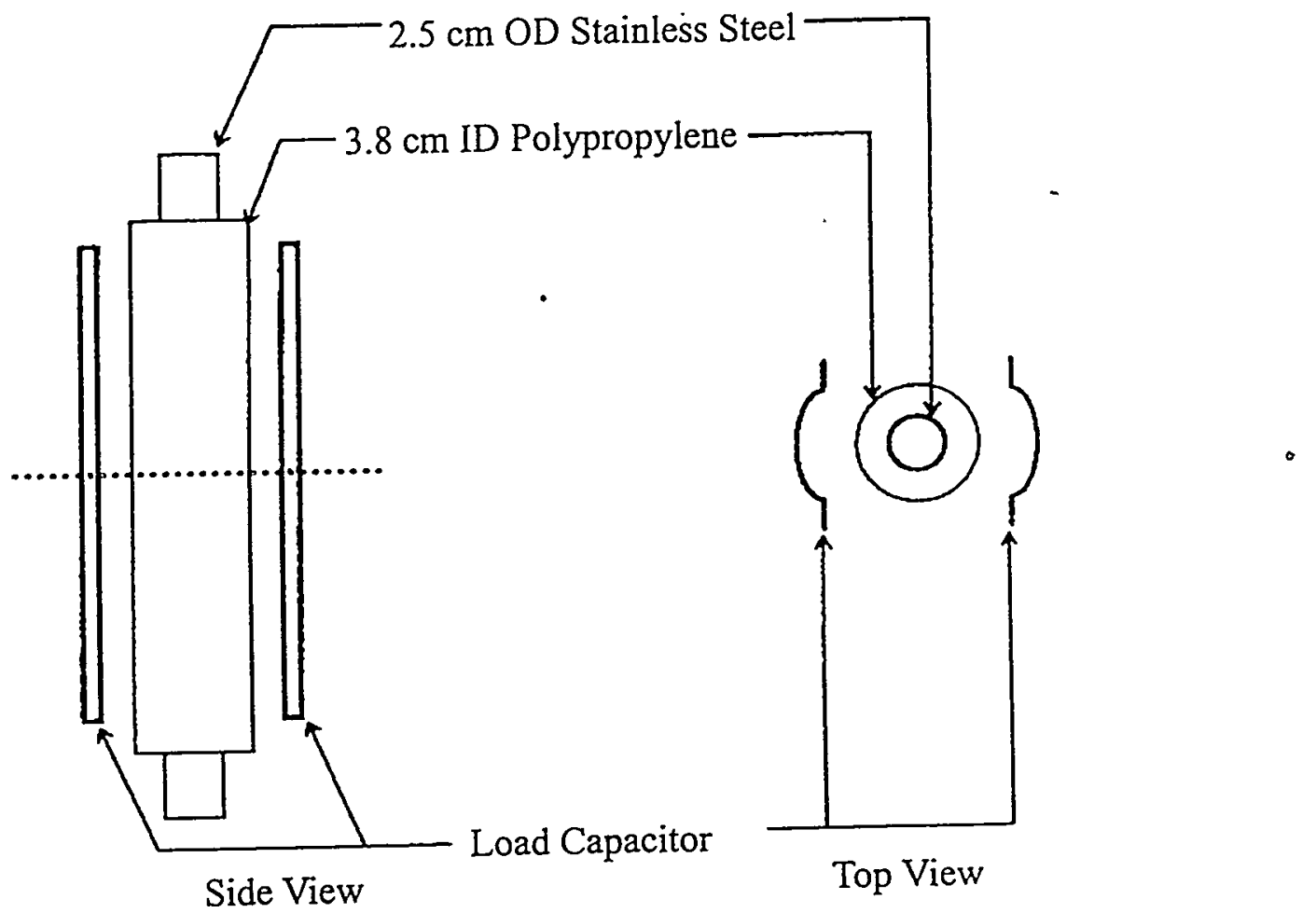


Plate Supply

2 - $12 \mathrm{KV}$

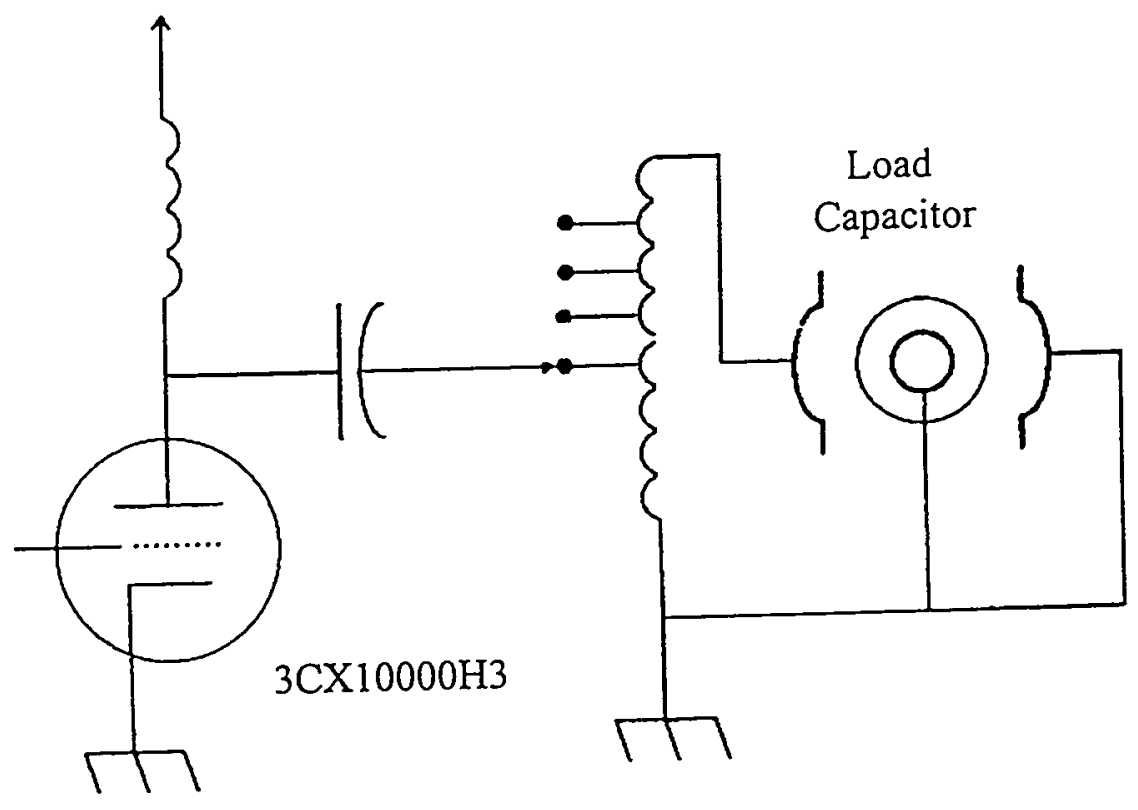




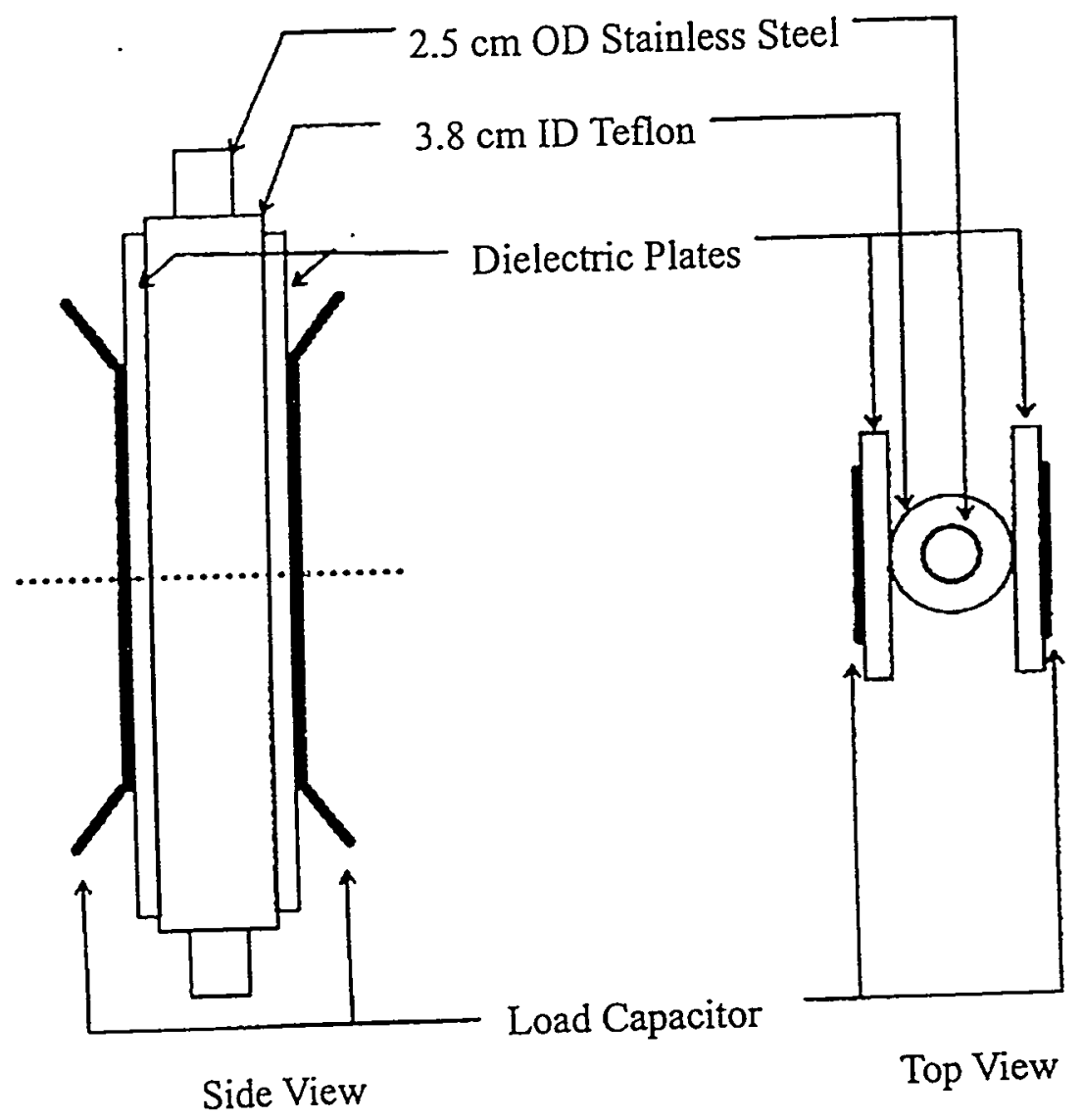


Plate Supply

2 - $12 \mathrm{KV}$

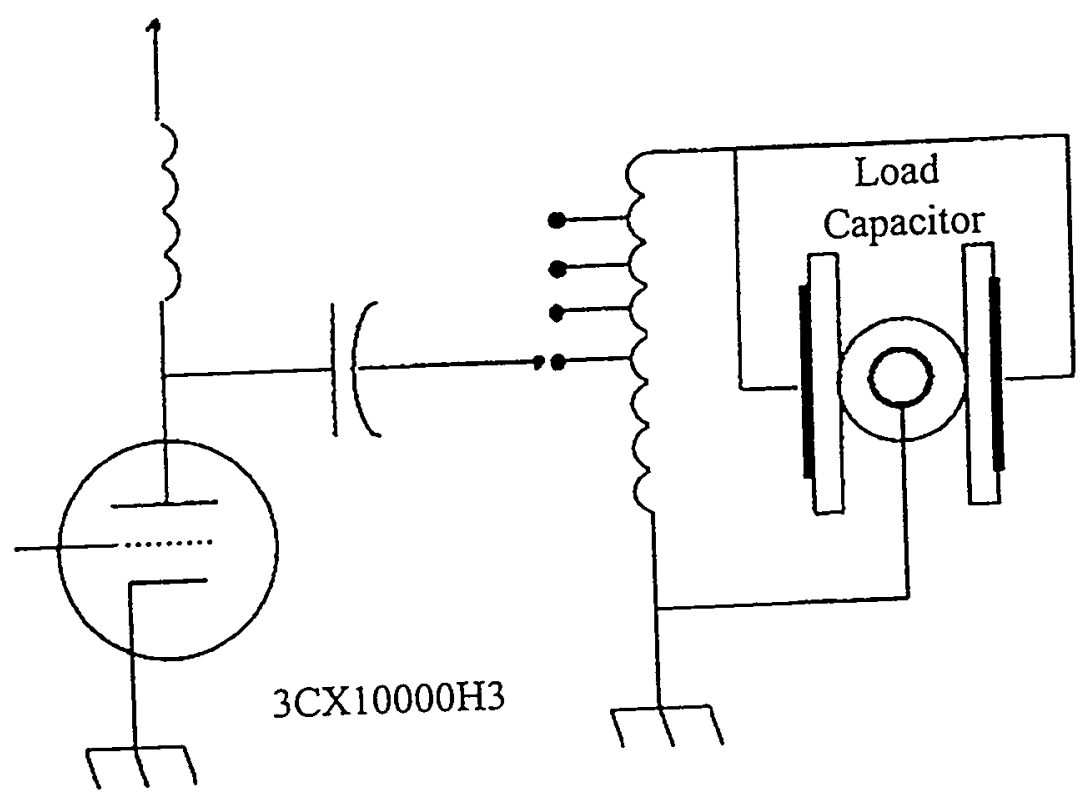




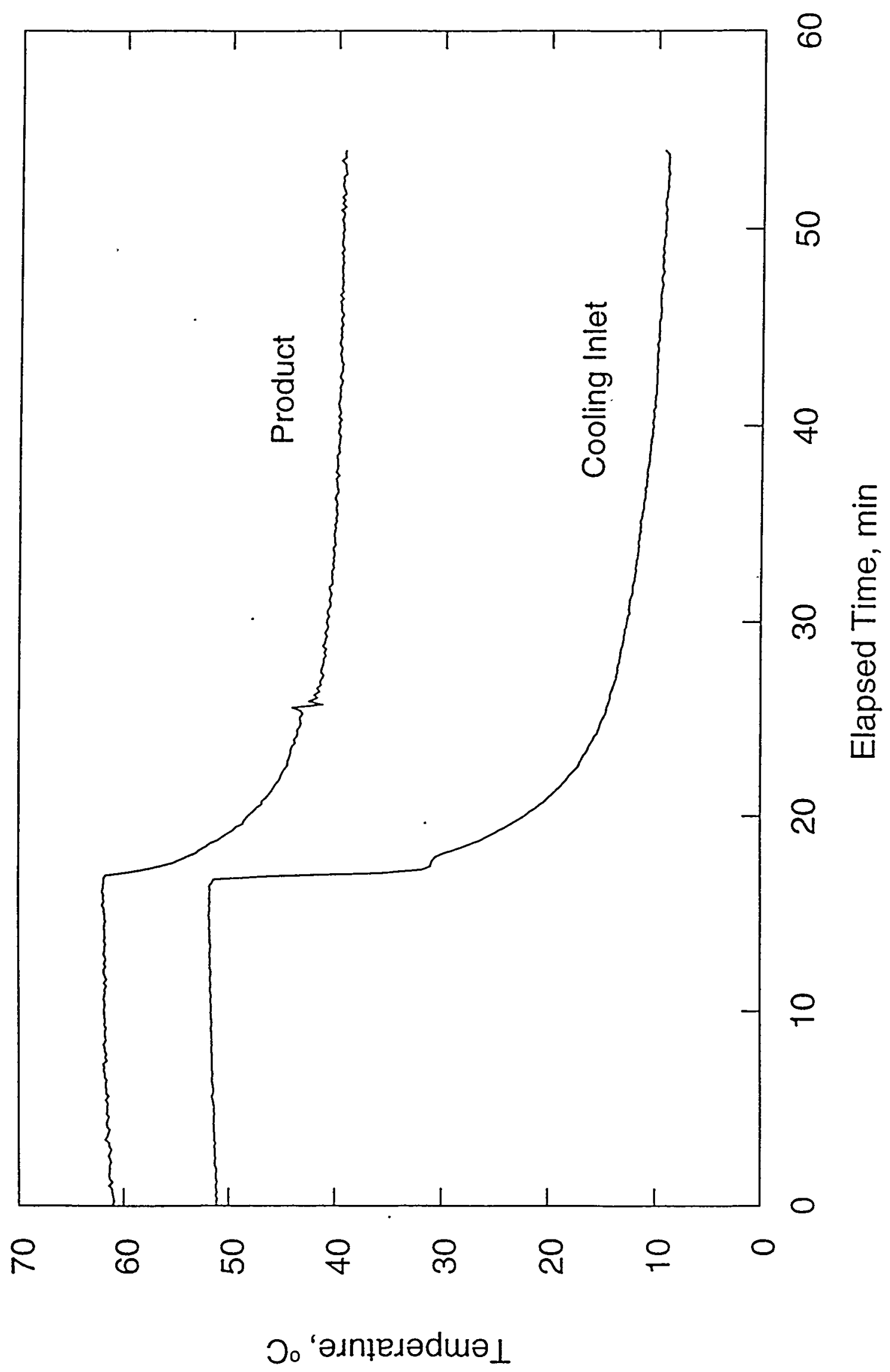

